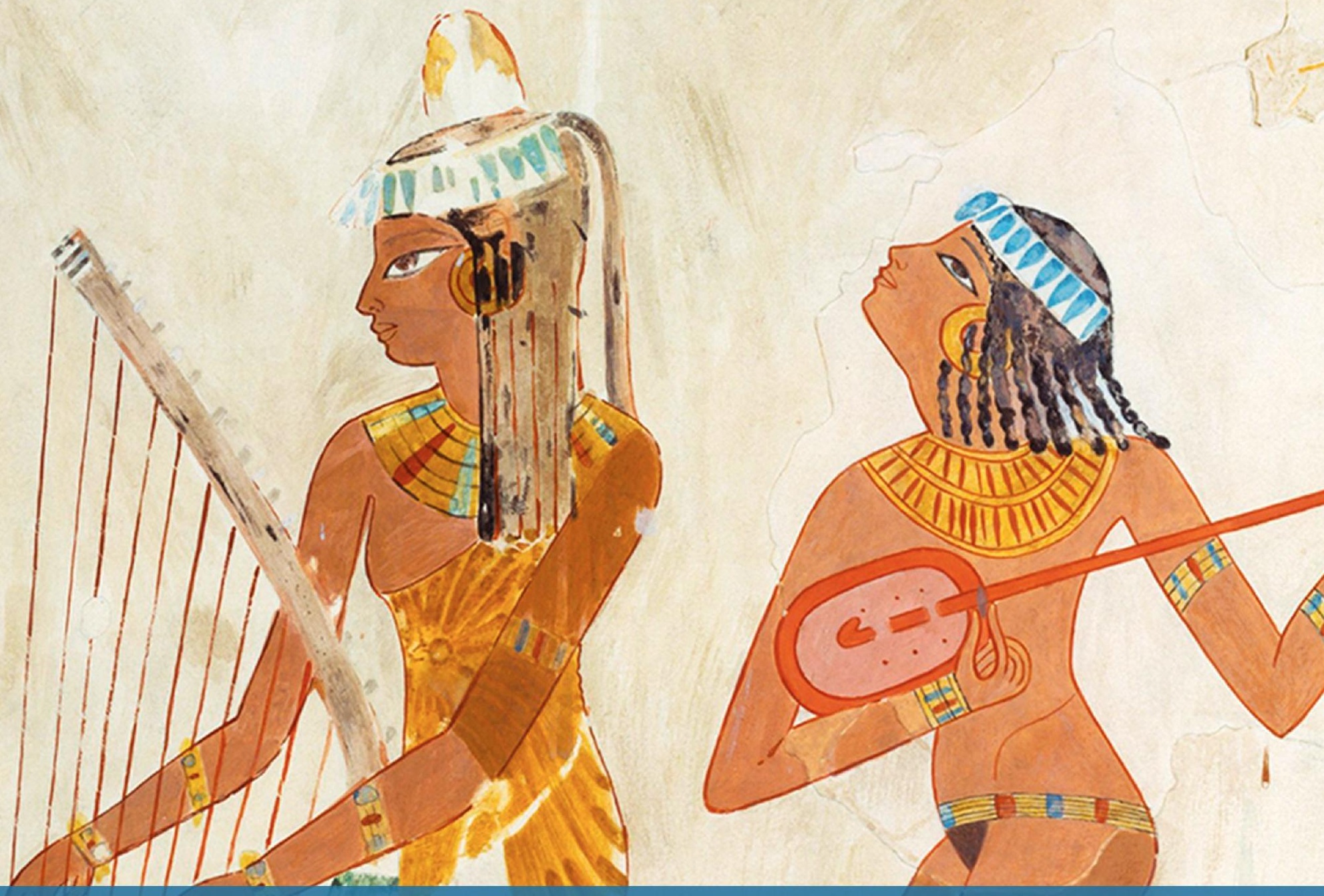

Revista digital de ciencia y Didáctica de la Historia

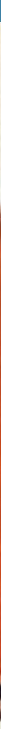




\section{Panta Rei \\ Revista Digital de Ciencia \\ y Didáctica de la Historia}

\section{9}

Revista anual

Fecha de inicio: 1995

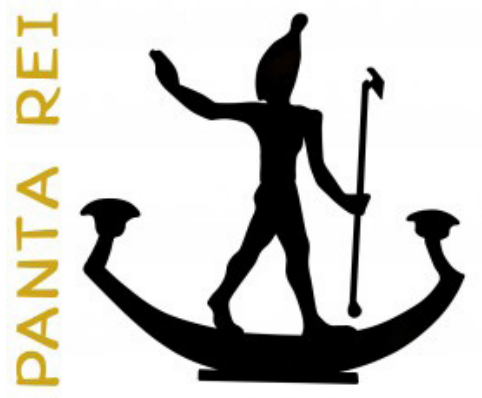

Revista Panta Rei. pantarei@um.es

Edita:

Centro de Estudios del Próximo Oriente y la

Antigüedad Tardía - CEPOAT

Edificio Universitario Saavedra Fajardo.

Universidad de Murcia

C/ Actor Isidoro Máiquez, 9

30007 - MURCIA - ESPAÑA

Teléfono: (+34) 868883890

cepoat@um.es

Web: www.um.es/cepoat/pantarei

Edición 2019

ISSNe: 2386-8864

Responsable de la presente edición: Consejo Editorial Panta Rei.

UNIVERSIDAD DE MURCIA centro de estudios del próximo oriente y la antigüedad tardía

En Portada: Fragmento de pintura de la tumba de Djeserkareseneb (TT38), Tebas. (fotografía del Metropolitan Museum).

Responsables de los textos: Sus autores.

ISSN: 1136-2464

Depósito legal: MU-966-1995 


\section{CONSEJO DE REDACCIÓN}

\section{Coordinador editorial}

Egea Vivancos, Alejandro

[Didáctica de las Ciencias Sociales, UMU]

\section{Editores}

Jiménez Vialás, Helena

[UMU]

López Muñoz, Dámaris

[UJA]

Meseguer Gil, Antonio José

[CEPOAT, UNED]

Sáez Giménez, David Omar

[CEPOAT, UMU]

Sánchez Mondéjar, Celso Miguel

[Patrimonio Inteligente]

\section{Secretaria}

Arias Ferrer, Laura

[Didáctica de las Ciencias Sociales, UMU]

\section{Responsable informático}

Martínez García, José Javier

[CEPOAT, UMU]

\section{Traducción y corrección lingüística}

Martínez Martínez, Cristina

[Sociedad Española de Lenguas Modernas]

Albaladejo Albaladejo, Sara

[ISEN, UMU]

\section{CONSEJO ASESOR}

Adroher Auroux, Andrés María [Arqueología, Universidad de Granada]

Albero Muñoz, M. ${ }^{a}$ del Mar [Historia del Arte, Universidad de Murcia]

Alia Miranda, Francisco [Historia Contemporánea, UCLM]

Arciniega García, Luis [Historia del Arte, Universidad de Valencia]

Barrio Barrio, Juan Antonio [Historia Medieval, Universidad de Alicante]

Castellano i Solé, Núria [Egiptología, Schola Didàctica Activa S.L.]
Chapman, Arthur [History Education, University College of London, Reino Unido]

Cid López, Rosa María [Historia Antigua, Universidad de Oviedo]

Cobacho López, Ángel [Derecho, Universidad de Murcia]

Cuenca López, José María [Didáctica de las Ciencias Sociales, Universidad de Huelva]

Egea Bruno, Pedro M. ${ }^{a}$ [Historia Contemporánea, Universidad de Murcia]

Feijoo Martínez, Santiago [Arqueología, Consorcio Ciudad Monumental de Mérida]

García Atienzar, Gabriel [Prehistoria, Universidad de Alicante]

Ginestí Rosell, Anna [Filología Clásica, Katholische Universität Eichstätt-Ingolstadt]

González Monfort, Neus [Didáctica de las Ciencias Sociales, Universidad Autónoma de Barcelona]

González Soutelo, Silvia [Arqueología, Universidad de Vigo]

Haber Uriarte, María [Prehistoria, Universidad de Murcia]

Hernández de la Fuente, David [Historia Antigua, Universidad Complutense]

Hutson, Scott R. [Anthropology, University of Kentucky, EE UU]

Igual Luis, David [Historia Medieval, UCLM]

Irigoyen López, Antonio [Historia Moderna, Universidad de Murcia]

Jover Maestre, Francisco Javier [Prehistoria, Universidad de Alicante]

Mahony, Simon [Digital Humanities, University College of London, Reino Unido]

Marsilla de Pascual, Francisco Reyes [Técnicas historiográficas, Universidad de Murcia]

Martínez-Burgos García, Palma [Historia del Arte, UCLM]

Mathis, Christian [Didaktik der Geschichte, PH Zürich]

Miralles Maldonado, José Carlos [Filología Clásica, Universidad de Murcia]

Molina Gómez, José Antonio [Historia Antigua, Universidad de Murcia]

Mónica Ghirardi [Historia Moderna, Universidad Nacional de Córdoba, Argentina]

Navarro Espinach, Germán [Historia Medieval, Universidad de Zaragoza]

Noguera Celdrán, José Miguel [Arqueología, Universidad de Murcia]

Ortiz Heras, Manuel [Historia Contemporánea, UCLM]

Panzram, Sabine [Historia Antigua, Universität Hamburg]

Pérez Molina, Miguel Emilio [Filología Clásica, Universidad de Murcia]

Prados Martínez, Fernando [Arqueología, Universidad de Alicante]

Sánchez Ibáñez, Raquel [Didáctica de las Ciencias Sociales, Universidad de Murcia]

Sancho Gómez, Miguel Pablo [Educación, UCAM]

Victoria Moreno, Diego [Historia Contemporánea, UNED]

Vilar García, María José [Historia Contemporánea, Universidad de Murcia]

Vivas Sainz, Inmaculada [Historia del Arte, UNED]

Zamora López, José Ángel [Próximo Oriente Antiguo, CCHS-CSIC] 



\section{Índice}

\section{Artículos}

La imagen de la Prehistoria en el cine y los géneros del cine prehistórico. Un mundo de hombres mono, bikinis y dinosaurios.

Alberto Lombo Montañés.

Trabajo y roles de género durante la Prehistoria. Un estudio sobre su percepción en el alumnado de Historia.

María Pastor Quiles y Daniel Mateo Corredor.

Memoria cultural en el Egipto Faraónico. Algunas reflexiones sobre su origen, función y pervivencia histórica.

Antonio Pérez Largacha.

La representación de la danza dentro de las escenas de banquete de las tumbas tebanas privadas de la XVIII dinastía egipcia.

Miriam Bueno Guardia.

La "Sala del Fresco" de Micenas. Revisión de las interpretaciones del programa iconográfico y nueva lectura en relación a los espacios.

Pelayo Huerta Segovia.

Las advertencias de Quilón y Solón sobre la tiranía de Pisístrato.

Unai Iriarte.

La Virgen de la Leche. Arquetipo de mujer y madre en la pintura del Renacimiento español.

Patricia Castiñeyra Fernández

Innovación didáctica en Historia: un estado de la cuestión en torno a cuatro ejes temáticos.

Diego Luna Delgado.

\section{Reseñas}

Foster, B. R. (2016), The Age of Agade. Inventing empire in ancient Mesopotamia, Londres y Nueva York: Routledge, 438 págs.

Juan Álvarez García.

Alviz Fernández, M. y Hernández de la Fuente, D. (Eds.) (2017). De ópos a limes: el concepto de frontera en el mundo antiguo y su recepción. Madrid: Escolar y Mayo editores. 256 págs.

Ethan Yepes de la Hoz.

Clares Clares, M ${ }^{\mathrm{a}}$ E. (2017). Música y noches de moda. Sociedades, cafés y salones domésticos de Murcia en el siglo XIX. Murcia: Universidad de Murcia, Servicio de Publicaciones. 474 págs.

Elena Micó Terol 195

Goñi Zabalegui, A. (2018). Género y sociedad en el Egipto romano. Una Mirada desde las cartas de mujeres. Oviedo: Ediciones de la Universidad de Oviedo. 360 págs.

Alejandra Izquierdo Perales. 199

Normas de publicación/Publishing rules 



\title{
Memoria cultural en el Egipto Faraónico. Algunas reflexiones sobre su origen, función y pervivencia histórica
}

\author{
Cultural Memory in Ancient Egypt. Some Reflections on Its Origin, Function and \\ Historical Endurance
}

\author{
Pérez Largacha, Antonio ${ }^{1}$ \\ Universidad Internacional de La Rioja (UNIR)
}

Recibido: 29/01/2019

Aceptado: 08/05/2019

Para citar este artículo: Pérez Largacha, A. (2019). Memoria cultural en el Egipto faraónico. Algunas reflexiones sobre su origen, función y pervivencia. Panta Rei. Revista Digital de Ciencia y Didáctica de la Historia, 55-68.

ISSNe: 2386-8864

DOI: $10.6018 /$ pantarei/2019/03

\section{Resumen}

Los estudios de J. Assmann sobre las características que tiene la memoria cultural en las primeras civilizaciones han originado diferentes debates además de haber abierto nuevas líneas de investigación. En este trabajo analizaremos qué se entiende por memoria cultural para, posteriormente, buscar los orígenes de dicha memoria cultural del Egipto Faraónico cuando apareció el Estado y en tiempos predinásticos. Con posterioridad comprobaremos cómo la memoria cultural pervivió en el Egipto faraónico a lo largo de más tres mil años de historia.

Una memoria cultural que se transmitió a través de los textos y, especialmente, de una forma visual con los monumentos, funerarios o no, que transmitían no solo unas creencias funerarias, también una concepción del mundo en el que los antiguos egipcios vivieron. La estrecha relación que existió entre dicha memoria cultural y lo que los antiguos egipcios veían en su entorno explica la perdurabilidad, no solo de sus creencias, también de una civilización que fue capaz de emitir unos mensajes que eran entendidos por todos los miembros de la sociedad.

\section{Palabras clave}

Historia Antigua, yacimientos, hermenéutica, Historia de Oriente Próximo.

\begin{abstract}
J. Assmann's studies on the characteristics observed by the phenomenon known as cultural memory in the earliest civilizations have given rise to various debates and, at the same time, it has opened new lines of research. In this paper, we shall discuss the concept of cultural memory in the Pharaonic Egypt and its origin in predynastic times and whe the State was created. Pharaonic Egypt. A cultural memory that survived through over three thousand years of history.

A cultural memory which was transmitted through the texts and, especially, in a visual way with

1 Para contactar con el autor: Antonio Pérez Largacha. Universidad Internacional de La Rioja (UNIR). antonio.perezlargacha@unir.net. ORCID 0000-0002-4459-394X.
\end{abstract}


the monuments, funerary or not, that transmitted not only religious beliefs, but also a conception of the world in which the ancient Egyptians lived. The close relationship which existed between the aforementioned cultural memory and what the ancient Egyptians saw in their environment, explain the strength not only of their beliefs, but also of a civilization that was able to emit messages that were understood by all the members of the society.

\section{Keywords}

Ancient History, Historic sites, Hermeneutics, Middle Eastern History.

\section{Introducción}

Los planteamientos que Jan Assmann ha realizado sobre la importancia y función que la memoria cultural disfrutó en el mundo faraónico, pero también en otras culturas (Assmann, 2005a)2 han tenido una extensa repercusión en diferentes ámbitos de la investigación (cf. Harth, 2008 sobre los orígenes de la llamada escuela de Heidelberg) (Erll, 2011; Wagoner, 2017). Asimismo, Jan Assmann, ha ido extendiendo el impacto de dicha memoria cultural a otros períodos históricos y a temáticas como el impacto que tuvo la aparición de las religiones monoteístas (Assmann 2006, 2017).

Como premisa inicial para los planteamientos sobre la memoria cultural se acepta que toda cultura, civilización y sociedad dispone de una memoria, tanto individual como colectiva a través de la que se establecen determinadas convicciones e ideas sobre el presente que se vive, basándose en la percepción y transmisión que del pasado se hace, un pasado que se ha ido creando, modelando y que puede tener diferentes objetivos y expresiones. Una memoria cultural que crea y mantiene una identidad social al vincular el presente con un pasado que lo justifica y legitima.

Según Assmann la memoria cultural es una forma de memoria colectiva, en el sentido de que la misma es compartida por un cierto número de personas y transmite un sentido colectivo cultural, de identidad. Por otra parte, es muy importante tener en consideración quién y cómo se crea dicha memoria, que razones se tienen para ello y como va a ser mantenida.

Una memoria cultural que se desarrolla y transmite a través de una comunicación escrita y visual que siempre recuerda lo que sucedió al conjunto de la sociedad y que es diferente a lo que Assmann (2008) denomina la memoria comunicativa, que afecta e influye a los miembros de una generación que comentan o comparten lo que les sucede. La memoria cultural se construye a partir de los ritos, las imágenes, los símbolos, los mitos y los textos literarios, por lo que no entiende de generaciones, una memoria cultural que es visible al exteriorizarse y ser conservada por las instituciones estatales con sus construcciones, símbolos o ritos.

En este sentido también podrían incluirse los mitos, fundacionales o no, que también tuvieron la función de validar e introducir a los miembros de la sociedad, desde su infancia y a lo largo de toda su vida, en una sociedad que tenía sus propias formas de actuar y valores (Buxton, 1994). Es decir, los mitos como parte de una identidad y reflejo de un pasado que sirve de modelo para el presente y de preparación para el futuro.

Otro aspecto diferente es qué sucede con posterioridad, cuando la cultura/sociedad que ha creado y ha vivido en una memoria cultural, que la ha dotado de unos signos de identidad y pertenencia, desaparece. En algunos casos dicha memoria puede pervivir integrándose en las nuevas concepciones que se desarrollan o como símbolo de un pasado que no tiene nada que ver con el presente pero que es visible, creándose así nuevas imágenes y mitos sobre ese pasado que es valorado como algo lejano, pero que al mismo tiempo se le dota de una autoridad, de una

2 En las próximas páginas utilizaremos la traducción española realizada por Assmann (2011). Jan Assmann estudio egiptología y arqueología clásica, siendo catedrático de egiptología en Heidelberg entre 1976 y 2003. Junto a su mujer, Aleida Assmann, desarrollaron la teoría de la memoria cultural que con anterioridad estaba englobada en lo que se calificaba como memoria colectiva. 
sabiduría, en ocasiones primigenia, como sucede con la mitología y la cultura grecorromana en la sociedad occidental.

También su desaparición puede ocasionar un vacío y olvido, aunque pervivan sus manifestaciones culturales, como fue el caso del antiguo Egipto o las culturas próximo-orientales. Así, la memoria cultural del Egipto faraónico pervivió hasta prácticamente el final del Imperio Romano, llegándose a integrar en algunos aspectos incluso en la iglesia copta, que encontró en la iconografía y símbolos faraónicos un medio de transmitir un nuevo mensaje al conjunto de la población (Frankfurter, 1998).

Sin embargo, con la expansión del Islam, dicha vinculación con el pasado fue desapareciendo, al tiempo que se generó la imagen de que el mismo no tenía nada que ver con el nuevo presente. Aun así, no se pudieron eliminar los vestigios arqueológicos que permanecían visibles, desde las pirámides a los templos o las tumbas faraónicas, sin olvidar los objetos, de carácter religioso o no, que afloraban a la vista en cada momento. Es decir, la memoria cultural que visualmente creó el mundo faraónico pervivió, pero ahora transmitía otros mensajes, como el de unos tesoros que permanecían ocultos bajo la arena del desierto, el de un conocimiento arcano que se había perdido y escondía unos secretos, o el de unas fuerzas mágicas que habitaban dichos vestigios que ahora llamamos arqueológicos (El-Daly, 2005), lo que en opinión de Stephan (2017) debe considerarse como algo lógico, y no despectivo, al existir la necesidad de integrar el paisaje faraónico que era visible.

En las próximas páginas nuestra intención será la de analizar cómo surgió la memoria cultural del mundo egipcio y perduró durante más de tres milenios de historia. Los planteamientos que realizaremos no pretenden analizar todas sus manifestaciones, ni sus pervivencias actuales, lo que sería algo demasiado ambicioso.

\section{El antiguo Egipto y la creación de una memoria cultural}

En opinión de Assman (2011), toda cultura crea lo que llama su propia "estructura conectiva", cuya finalidad es la de unir y vincular la dimensión social con la dimensión temporal; en definitiva, crear y desarrollar un mundo simbólico que reúna unas experiencias y mensajes que sean vividas y sentidas por igual, para generar de ese modo un marco de confianza y seguridad.

Para alcanzar dicha conectividad el mundo faraónico recurrió al arte, al poder de las imágenes y también a los textos, ya que, aunque solo una mínima parte de la población pudiera leer los textos (Baines y Eyre, 1983), la relación entre texto e imagen está presente desde los orígenes de la escritura (Piquette, 2018) y se unieron en la decoración de los templos, en las estelas conmemorativas o en multitud de objetos.

Los templos, con sus ritos y ceremonias que englobamos en lo que entendemos como religión, en el antiguo Egipto no tenían dicha calificación. Como señala Pongratz-Leisten (2019) para el mundo mesopotámico, la religión se ha entendido como un sistema cultural que existió entre otros -la política, la economía, la literatura o el arte-, disfrutando cada uno de libertad en lugar de asumir que todos ellos forman parte de una misma realidad, sucediendo lo mismo en la investigación y conocimiento del antiguo Egipto.

Religión y Estado son dos entidades similares, difíciles de diferenciar y que están unidas en la figura del Faraón, que actúa como representante de los dioses en la tierra para mantener un orden cósmico que había sido establecido en la creación, un orden que debía ser mantenido y protegido al encarnar todos los valores del mundo faraónico y, lo más importante de todo, su pervivencia (O'Connor y Silverman, 1995; Morris, 2013).

Los orígenes de esta simbiosis entre realeza, estado y religión se remontan a tiempos predinásticos, cuando se instituyó un modelo de realeza y unos rituales del que emergió una figura del Faraón que estaba en estrecha relación con los dioses, lo que aportaba confianza y seguridad al conjunto de la población, al tiempo que se procedía a explicar el mundo; la cosmovisión de las primeras religiones que ponía a la religión al servicio del Estado y que, en opinión de Assmann 
(2006), es el paso previo del posterior monoteísmo.

Como sucedió a finales del período Uruk en Mesopotamia (Frangipane, 2018), quedó instituida la estrecha relación que existía entre el gobernante, los dioses y sus templos, y todo ello en un contexto ceremonial que transmitía un control ideológico. A ello se unió en el antiguo Egipto, desde tiempos de Nagada II (ca. 3.300 a.C.), unas tumbas que se fueron convirtiendo en expresiones visuales del poder del Faraón y de una vinculación cada vez más estrecha con los dioses.

Es así como los rituales, incluidos los funerarios, la repetición constante de unas ceremonias, fueron fijando aún más las experiencias del pasado que legitimaban el presente. Unos ritos que se celebraban en unos lugares específicos, los templos, donde moran unos dioses que con su presencia avalan dicho orden (Baines, 1997; Shafer, 2005). Pero los ritos también se pueden y deben celebrar en otros ámbitos según sean las circunstancias de cada momento, como en el caso de las procesiones, que vinculan el espacio próximo y terrenal con el simbólico que representan los templos (Stadler, 2008).

Las procesiones, que pudieron ya celebrarse en tiempos previos a la unificación de Egipto a través del "ciclo real" (Williams y Logan, 1987), buscaban integrar a toda la sociedad en un mismo marco mental que la dota así de una identidad propia al tiempo que se van poniendo las bases de una diferenciación respecto a todo aquello que es externo y, por lo tanto, diferente, lo que se concretará en todo lo que rodea al valle del Nilo.

Por otra parte, dentro de ese ciclo real presente desde tiempos protodinásticos, está el propósito de presentar a los dioses unas acciones de gobierno. Una realidad que va a estar presente a lo largo de toda la historia de Egipto, bien presentando los logros militares -ciertos o no- pero que eran esperados y transmitían un mensaje comprensible de protección al conjunto de la sociedad, o bien realizando cualquier otro tipo de ofrenda, desde alimentos y productos internos o exóticos obtenidos más allá de las fronteras de Egipto o la que será también frecuente, la presentación de Maat a los dioses, el símbolo de que todas las acciones de gobierno del faraón estaban dirigidas, y conseguían mantener, el frágil equilibrio del orden (Manning, 2017).

Lógicamente, estos rituales y escenas que se grababan en las paredes de los templos, pero también en estelas u otros soportes, podían ser utilizados políticamente para justificar otras acciones de gobierno y transmitir otros mensajes, pero siempre debiendo estar presente la idea, el concepto y el mensaje de que todo respondía en realidad a unas normas y reglas que eran imprescindibles, las necesarias para la supervivencia de Egipto y, por tanto, de la población que en él vivía (Baines, 2007).

Igualmente, ese mundo que nosotros llamamos ritual también se traslada al mundo de los palacios, desde donde el Faraón administra y también garantiza la prosperidad y seguridad del conjunto de la sociedad (Bietak, 2018) y, posiblemente, también a las ciudades, aunque nuestro conocimiento de éstas en el antiguo Egipto es muy escaso (Yoffe, 2015).

Así, no deja de ser significativo que el primer nombre de los faraones egipcios lo encontramos en el llamado serekh. Sin entrar en el debate sobre su origen, lo que en el serekh se refleja es el mensaje, entendible por todo el que lo ve, de que el Faraón gobierna desde el palacio, siendo protegido y bendecido por Horus, la divinidad que se vincula con la realeza a través precisamente del famoso mito de Osiris sobre el que hablaremos más adelante, que de ese modo aprueba todas las acciones que el rey adopta.

Un mundo el de los palacios del que, por desgracia, apenas conocemos nada en el antiguo Egipto. De los escasos vestigios conservados se desprende que a través de su arquitectura y, en especial su decoración, se transmitía la imagen de un gobierno basado en unos principios que garantizaban el orden, la estabilidad y prosperidad. Así, podemos citar las conocidas representaciones e imágenes de los extranjeros, enemigos o no de Egipto, que se representan derrotados, dominados y cuya visión transmitía al mundo de la corte, y también al de los embajadores, comerciantes y príncipes o princesas extranjeros que vivían en Egipto el poder de Egipto y su gobernante, transmitiendo con posterioridad en sus respectivos reinos aquello que habían visto.

Lógicamente ésta no fue una manifestación únicamente faraónica, las apadanas del mundo 
aqueménida o los palacios neoasirios tenían la misma finalidad, transmitir un orden, un poder que lo protegía ante cualquier intento de desestabilizarlo (Heinz y Feldman, 2007). Unos mensajes que también estaban destinados a las personas más cercanas al faraón, a sus nobles y altos funcionarios que, en definitiva, eran aquellos que podían llegar a constituir un peligro, una amenaza interna para su poder (Yoffee, 2005).

Los ritos son importantes, pero también la existencia de un calendario religioso, no solo en el antiguo Egipto, también en cualquier sociedad, antigua o moderna. Codifican un conjunto de normas, unas formas de actuación, de pensar y de vivir, al tiempo que la sociedad conoce lo que se persigue obtener, alcanzar o mantener (Stern, 2012). Unos ritos que codifican unas ideas ahondando en la percepción y sensación de pertenencia a un grupo y que con su repetición constante desarrollan la sensación de pertenecer a una identidad unida por su pasado (Chaniotis, 2006; Hays, 2009), al tiempo que transmiten protección y confianza ante el futuro.

En el antiguo Egipto los orígenes de los ritos y ceremonias pueden encontrarse en tiempos predinásticos. Las excavaciones en Hierakómpolis han revelado la existencia de un centro ceremonial (HK29A), donde se realizaban todos los años ceremonias coincidiendo con el momento del año en que el nivel del Nilo era más bajo, con ofrendas de animales y objetos que simbolizaban el caos, el desorden, con la esperanza de que la crecida del Nilo retornara y propiciara el renacer de Egipto (Friedman, 2009). El temor a cómo sería la crecida y si tendría lugar siempre estuvo latente en el mundo egipcio, aunque no se expresara.

Unas ceremonias que irían acompañadas de actos en los que participaría gran parte de la comunidad de una forma directa o indirecta, como por ejemplo en la caza de los animales que eran ofrecidos o la preparación de los rituales y objetos que iban a ser utilizados. Es decir, desde tiempos predinásticos había un conocimiento y una participación de la sociedad en todo lo que debía realizarse para propiciar el futuro y, en definitiva, que el presente llegara a ser como el pasado por el bien del futuro.

En los llamados objetos protodinásticos, como en la paleta de Narmer, encontramos unas escenas que tienen un carácter ritual. A través de ellos la naciente realeza faraónica transmite sus logros, su relación con los dioses y va fijando las formas de representar el mundo ordenado, con una proporción jerárquica, unos símbolos asociados a la realeza y a sus más directos seguidores, en unas acciones que son observadas por los dioses que bendicen, aprueban lo que se realiza y todo en ello en un entorno público.

Igualmente, desde los primeros anales o documentos escritos que conocemos del antiguo Egipto, el mensaje que se transmite en todos ellos es que los faraones realizan los festivales de los templos más importantes, construyen las estatuas de las divinidades o derrotan a los enemigos del caos circundante (Piquette, 2018). Es por ello por lo que adquiere un mayor significado, además del histórico con el que historiográficamente son asimilados los anales reales, que dichos textos sean depositados o representados en el interior de los templos (Baines, 2008).

Con la unificación de Egipto y el nacimiento del Estado todo el poder se centraliza, desde los recursos económicos hasta el funcionamiento de la administración, accediendo a los títulos y cargos los círculos más próximos a la figura del faraón, sus familiares. Se crea una organización social y política alrededor de faraón, que encarna el vínculo con el pasado, el poder presente y la garantía de prosperidad (Wilkinson, 2016).

También desde comienzos de Nagada II, se constata una creciente importancia de las tumbas, no solo por su tamaño o riqueza en el ajuar, sino por su visibilidad, lo que transmite que allí está enterrado el líder que les ha protegido y guiado, al tiempo que se van poniendo las bases de un paisaje sagrado (Hartung, 2018).

Por todo ello, y después de un largo proceso de conquista y dominio del entorno geográfico que se remonta al Holoceno, se fijaron las bases de un Estado y una realeza que expresaba los logros obtenidos y lo que debía preservarse, unas realidades que eran visibles y que ya formaban parte de la memoria cultural. 


\section{Memoria cultural y sociedad}

En relación con los ritos, ceremonias y los ciclos reales también están los relatos míticos e históricos, así como los relatos literarios (Loprieno, 1996), que contribuyen a vincular y crear una identidad. En ellos casi siempre aparece una breve descripción del pasado, un recuerdo de lo que se ha vivido que se rememora, así como las normas y valores que son comunes que sirven para expresar lo que se esperaba y debía realizarse, lo que Assmann (1999) denomina como "textos culturales" (Baines, 2003).

Uno de los aspectos que siempre ha sorprendido del antiguo Egipto es la práctica ausencia de mitos, que en opinión de Assmann no aparecen hasta avanzado el Reino Nuevo (Assmann, 1977; Goebs, 2002). No podemos entrar en un debate que nos apartaría en demasía de nuestras intenciones, pero sí creemos que las historias de los mitos faraónicos eran conocidas por el conjunto de la sociedad, por lo que no existió la necesidad de crear unos textos escritos que codificaran las ideas debido, como veremos, a que no existió un sacerdocio profesional hasta el Reino Nuevo y que con anterioridad el conjunto de la población participaba en las actividades del templo, sabiendo lo que simbolizaba y para qué, conociendo así las historias y por qué para ellos eran importantes. Es decir, se está contribuyendo a mantener una memoria cultural.

En líneas generales los mitos egipcios responden a unas ideas básicas y comunes que encontramos reflejados en otros ámbitos de la sociedad; un orden, una estabilidad que sufre en momentos determinados una quiebra, una amenaza debiéndose recuperar lo inicial, un pasado y origen que implica estabilidad y seguridad.

El mito más conocido del mundo faraónico es el de Osiris, su muerte a manos de su hermano Seth y la posterior venganza y victoria de Horus para restablecer el orden, versión que conocemos en su totalidad gracias a Plutarco (Griffiths, 1970). Además de la vinculación que en el mito se establece entre Horus y el Faraón, de Osiris con la muerte y la regeneración y de Seth con el caos (Mathieu, 2011), también se transmite que se ha de estar siempre vigilante ante unos peligros que pueden y deben ser derrotados, pero que en ningún momento llegan a ser destruidos en su totalidad, que pueden reaparecer en cualquier situación y momento, es decir, nuevamente el vínculo entre el pasado, presente y el futuro, una realidad que era vivida, sentida y conocida por el conjunto de la sociedad (Quirke, 2015).

Así, en el ámbito de la vida cotidiana, la población debía protegerse contra numerosos y variados peligros, desde los animales que podían causar la muerte o daños en las cosechas a fenómenos que periódicamente venían de los límites de Kemet, Egipto, para perturbar la estabilidad; como tormentas de arena o la inseguridad ante la próxima crecida. Es decir, la población sabía que debía mantener unas normas, unas actitudes y valores que como comunidad le permitían no solo protegerse, sino también vencer periódicamente a lo que debían enfrentarse y temían. Cada persona o comunidad participaba en su entorno en el mantenimiento de un orden que, a nivel estatal, estaba encarnado en el Faraón, en Horus, la superestructura.

Como hemos mencionado, hasta el Reino Nuevo no existió en Egipto un clero profesional y, aun entonces, solo en relación con los templos más importantes (Spencer, 2010). Entonces ¿Quién trabajaba o realizaba todos los trabajos que debían realizarse en el templo?

En primer lugar, debemos precisar que el templo egipcio no debe entenderse solamente como un centro religioso, también era una entidad económica, administrativa, con sus propios recursos destinados no solo a su propio mantenimiento, también al del conjunto de la comunidad.

Lógicamente los altos cargos estuvieron vinculados con el poder real o provincial, pero el conjunto de "sacerdotes" serían miembros de la comunidad que dedicaban una parte del año en trabajar y realizar diferentes actividades en ellos por un sistema de rotación. Es decir, la población conocía y participaba en todo lo que el templo simbolizaba, las razones por las que se realizaban diariamente las ceremonias de alimentar, vestir, lavar o perfumar las estatuas de los dioses al amanecer, símbolo de un nuevo renacer tras haberse superado el peligro de la oscuridad y la noche. De ese modo la población interiorizaba lo que el templo simbolizaba, lo que era de memoria 
y vínculo con el pasado para preservar el presente. No hacían falta textos, liturgias o ceremonias públicas que explicaran a la sociedad las normas, los peligros o la necesidad de realizar unos ritos que garantizaban su propia seguridad.

En los últimos años se están interpretando los rituales como algo vivo y cambiante que se van adaptando tanto a las necesidades que van surgiendo como a los cambios que tienen lugar en las sociedades (Ristvet, 2015). Igualmente, se comienzan a valorar los aspectos sensoriales asociados a los mismos, a lo que se veía, a lo que se sabía que se hacía, lo que se oía y representaba en definitiva en todo ritual, funerario o no, y cómo ello era interiorizado por la comunidad (Butler y Bradley, 2019).

Unas realidades y sensaciones que emitían unos símbolos, unas ideas que después serían transmitidas por todos aquellos que habían participado en los rituales a sus respectivos ámbitos domésticos o de grupo. Es decir, los rituales podían ser restringidos, pero lo que en ellos se realizaba, para qué y por quién era conocido por todos, manteniendo de esa forma la memoria cultural unida.

Un ejemplo pueden ser los rituales funerarios. Los realizados en el ámbito real tendrían sus características y son los más conocidos, pero en todos los niveles de la sociedad serían realizados según sus recursos y posición social, no debiendo olvidar que además estamos ante un momento y situación liminal, donde habría sentimientos, celebraciones, canticos, duelos, comidas y, finalmente, pero no menos importante, también un recuerdo hacía los antepasados (Harrington, 2012).

Es importante tener en consideración estos aspectos de los rituales y de la participación en los templos porque los mismos reflejan una transmisión de las concepciones, temores y esperanzas de la población en todos los niveles, pero expresados a nivel cotidiano, de grupo, no de una forma global o estatal como sucede en el ámbito de las expresiones reales, pero en ambos casos se están reproduciendo las mismas ideas y todas ellas forman parte de la memoria cultural de un pueblo.

En este sentido de comunicación, vivencia y transmisión de conceptos e ideas que forman parte de la memoria cultural no podemos olvidar el ámbito doméstico en el que las mujeres tenían un papel fundamental. En el mismo radicaba, como lo ha hecho a lo largo de la historia, la educación e integración de las futuras generaciones en la sociedad en la que iban a vivir, los valores y normas que la regían, qué se esperaba de ellos y cómo debían actuar (Robins, 1993). Un ámbito doméstico que mantenía y transmitía las normas, las ideas y valores que encarnaba la sociedad en la que se vivía, introduciendo a todos sus miembros en la memoria cultural.

Por otra parte, siempre se destaca el volumen de ofrendas, alimentos o tierras de que disponían los templos, en especial a partir del Reino Nuevo, pero en todo momento existieron las ofrendas reversibles, es decir, una vez que las ofrendas materiales habían realizado su función espiritual en los templos, como alimentar a los dioses, la parte física de las ofrendas se redistribuía en la comunidad, aumentando así la sensación de permanencia, de identidad con unas estructuras que no estaban aisladas de la sociedad, sino integradas en ella (Teeter, 2011).

En definitiva, lo que se realizaba en los templos o en los rituales funerarios, tenía una repercusión en la sociedad, que constataba cómo se les protegía a un nivel global, de superestructura, mientras que su sentido de identidad quedaba fortalecido por unas costumbres y creencias que eran suyas y diferentes al mundo que les rodeaba.

\section{Memoria cultural y sus manifestaciones}

La memoria cultural de una civilización también se expresa en sus construcciones y relatos, contribuyendo de esa forma a visualizarla y que esté presente en todo momento.

La literatura, los textos literarios, están adscritos y vinculados con una élite gobernante, y desde el Reino Medio con una clase funcionarial, teniendo dichos textos el propósito de involucrar a funcionarios y escribas en las que iban a ser sus obligaciones, como mantener unas normas y propiciar un funcionamiento de la administración central que garantizaba la estabilidad presente, unos textos en los que encontramos continuas referencias al pasado, a cómo debían ser, funcionar y hacerse todas las obligaciones (Parkinson, 2002). 
Por otra parte, algunos textos literarios son cuentos, historias que seguramente habían circulado a un nivel oral durante mucho tiempo transmitiéndose de generación en generación hasta que, en un momento concreto, y por razones diferentes, se deciden "codificar". En definitiva, el papel de la oralidad en las sociedades antiguas, desdeñado en muchas ocasiones por lo que se ha llamado en ocasiones la "tiranía de lo escrito", que también tendría en el antiguo Egipto su importancia y presencia (Baines, 2007b).

Otra expresión que forma parte de la memoria cultural de una sociedad son sus monumentos, no solo por su monumentalidad, su cantidad y decoración en el caso faraónico, sino por su perdurabilidad en el tiempo, haciendo que ese pasado que sirve para vincularse con el presente esté presente en todo Egipto. Un ejemplo de ello es el conocido refrán árabe: "El hombre teme al tiempo y el tiempo teme a las pirámides".

Por ello la pregunta de ¿cómo se imaginan las sociedades al recordarse? adquiere en el caso del antiguo Egipto una significación especial. Su pasado era visible y si los antiguos griegos pensaron que los palacios y construcciones del mundo micénico solo pudieron ser construidos por los grandes héroes homéricos, ¿qué podrían pensar los egipcios de los monumentos, funerarios o no, que jalonaban Egipto? (Baines, 1989). Un pasado que se les presentaba glorioso, eterno y seguro, siendo manifestaciones de éste.

Toda sociedad siempre ha buscado, y lo sigue haciendo, unos vínculos con su pasado a través de edificios, construcciones o personajes con que se identifican dichas edificaciones y, por extensión, heroicas acciones de gobierno, de una victoria militar. Unos vínculos que construyen la identidad propia pero también les diferencia del resto, otra característica de toda memoria cultural, lo propio y lo externo, lo conocido y lo diferente, lo seguro y lo desconocido, en definitiva, la construcción del "otro" que da legitimidad y proporciona seguridad a lo que se conoce y donde se vive.

En algunos textos egipcios hallamos referencias al penoso estado en que se encontraban antiguas tumbas y construcciones debido al paso del tiempo y la ausencia de un mantenimiento, pero también son muchas las pruebas que reflejan una admiración constante por ese pasado, desde los grafiti -una documentación que en pocas ocasiones es investigada y valorada (Peden, 2001)- a las representaciones de antiguos monumentos.

Un contexto en el que no podemos olvidar al príncipe Khaemwaset, hijo de Rámses II, que es considerado en ocasiones como el primer arqueólogo de la historia. En sus textos proclama que se encargó de la restauración y cuidado de numerosos monumentos, aunque quizás su verdadera intención fuera la de encontrar materiales que pudieran emplearse en la ambiciosa política constructora de su padre (Malek, 1992).

Así, la reutilización de materiales y objetos por algunos faraones podría verse como una actitud meramente práctica, útil, pero algunos piensan que en esa utilización también pudo existir un deseo de vincularse con lo que esos materiales y objetos del pasado simbolizaban (Wendrich, 2013), nuevamente la unión del pasado cómo símbolo de la memoria cultural con el presente.

En opinión de Assmann (2011), el pasado no puede desaparecer del todo, siempre tiene que haber unos testimonios que lo hagan visible y que además establezcan una diferencia que sea característica respecto al presente de cada momento. Cómo sucedió en Mesopotamia (van de Mieroop 2012), el pasado nunca estaba lejos, era visible y sus principales manifestaciones, los templos, eran reconstruidos, ampliados o decorados constantemente al ser las casas de unos dioses que con su presencia garantizaban el orden y otorgaban protección.

Tebas fue la capital política de Egipto en el Reino Medio y Reino Nuevo, aunque la administración y el comercio tuvieran en el Delta su centro neurálgico. Los reyes tebanos de la XI dinastía que reunificaron Egipto tras un primer período intermedio de fragmentación política, pero de grandes cambios culturales, pronto procedieron a vincularse con un pasado que legitimaba el presente y cuando trasladaron la capital a Itjtawi, en las proximidades de el Lisht, construyeron sus complejos piramidales en los mismos lugares que lo habían hecho sus antecesores del Reino Antiguo y, además, procedieron a reutilizar muchos de los monumentos en beneficio propio.

Con posterioridad, en el Reino Nuevo, dio comienzo lo que se ha calificado como "nacionalismo 
tebano" que tiene en los templos, ceremonias y procesiones religiosas y, en especial, en las tumbas tebanas, su máxima expresión. Todo faraón del Reino Nuevo recuerda el pasado, es el que legitima, justifica que él gobierne, al tiempo que dicen hacer algo más y diferente a sus predecesores. Las condiciones de Egipto han cambiado, su integración en las dinámicas del Mediterráneo oriental hace que todo faraón exprese no solo proteger las fronteras de Egipto, también extenderlas, aunque no sea cierto, siendo significativo el paralelismo que existe con otros reinos e imperios de la Antigüedad, no solo del Bronce Reciente (Liverani, 1990), también el propio Imperio Romano.

Es el templo de Karnak el que mejor simboliza esta nueva dinámica. Todo faraón edifica algo en el mismo y dice completar lo iniciado por su predecesor, presentándose como continuador de un pasado. En el antiguo Egipto no tenemos las conocidas representaciones del rey constructor que existen en el mundo próximo oriental, desde tiempos sumerios al propio Asurbanipal, pero en ambos casos el mensaje es el mismo; son representantes de un presente que basa su gobierno en un pasado que es cuidado, mantenido y respetado (Waerzeggers, 2011).

Es de esta forma como algunos lugares y construcciones se semiotizan, es decir, adquieren un significado para las comunidades que ven en ellos unos símbolos, unos mensajes. En el mismo sentido, las ciudades del Próximo Oriente se estructuran en calles festivas por donde discurren las procesiones o se pueden ver los símbolos que encarnan ese presente pero que tienen sus raíces en el pasado.

El mejor ejemplo de esto último en el antiguo Egipto puede ser la ciudad de el-Amarna, donde su estructura urbana está pensada para que Akhenatón se traslade al comienzo de todos los días desde su palacio en el norte de la ciudad al centro administrativo y religioso acompañando así, mientras se traslada en su carro, al disco solar (Stevens 2015).

Un simbolismo urbano que apenas conocemos en el antiguo Egipto, pero que debió de existir, al igual que lo que se engloba, de forma genérica y global, bajo el término de "paisaje sagrado" y que vincula las tradiciones, los ritos y ceremonias con el presente, lo que conocemos mejor gracias al mundo mesopotámico y festivales como el del año nuevo que se celebraba en Babilonia.

En definitiva, una alianza entre el poder y el recuerdo que sirve para que el poder se legitime y sea perpetuo. Como señala Assmann (2011), en Egipto las imágenes funcionan como medio de la memoria cultural, siendo los templos la institución central de la misma.

Otro ejemplo son las representaciones victoriosas de los faraones sobre unos enemigos casi siempre poderosos y que, incluso, no podían haber sido derrotados por nadie con anterioridad. Un ejemplo es el de Ramsés III y sus relieves del templo funerario de Medinet Habu, origen de la concepción moderna de los "Pueblos del Mar", pero sus textos pudieron ser en su mayoría copiados de reinados anteriores y reunir, en el mejor de los casos, pequeñas victorias que fueron presentadas como una gran victoria (Cavillier, 2013).

Se podrían mencionar muchos y variados ejemplos, como los libios que son vencidos por Sahure, vuelven a ser derrotados por Pepi I y, por tercera vez, por Taharqa, el fundador de la XXV dinastía (Kahl, 2010), que era de origen nubio y encontró así una forma de vincularse con el pasado para legitimar el presente, algo aún más que necesario en su caso debido a su origen no egipcio.

Todo ello lo sabe y conoce la sociedad egipcia. Ya nos hemos referido a la transmisión de los valores y actitudes que cada miembro de la sociedad recibía y debía de tener a lo largo de su vida, lo que se esperaba de él y, posiblemente, la mejor prueba de ello sean las biografías funerarias. Como señala Assmann (2011), el funcionario egipcio realizaba su tumba y una biografía, pero no son unas memorias, sino una necrología anticipada. Es decir, cuando leemos un texto funerario sabemos lo que se nos va a transmitir, con un detalle mayor o menor y una calidad literaria o artística acorde con la posición del funcionario, pero lo que debía aparecer se conocía y respondía a todo lo que englobaba la memoria cultural faraónica; la preservación del orden, haber respetado las normas de Maat y servir con respeto y eficacia al Faraón, el representante de los dioses en la tierra.

Otro de los aspectos inherentes a toda memoria cultural es su relación con la historia. La memoria cultural no tiene por qué corresponderse con hechos históricos ciertos. Uno de los mejores ejemplos es el de Menes, el mítico fundador del Estado faraónico y que, historiográficamente se ha 
identificado con Narmer por lo representado en su famosa paleta. Pero no disponemos de ninguna prueba de la existencia de Menes, que pudo ser una invención en un momento histórico en el que el mundo egipcio, su élite política, requería de un anclaje, de un punto de partida que uniera el pasado y la sucesión dinástica que ellos encarnaban (Heagy, 2014).

Estos ejemplos históricos responderían a lo que Assmann (1991) califica como gran tradición, aquella que está vinculada con las élites gobernantes que son las que siempre han dominado el mundo faraónico y transmiten su visión. Pero también existiría lo que Bussman (2016) llama pequeñas tradiciones, difíciles de documentar pero que estaban presentes y que responderían, desde una perspectiva antropológica, a todo lo que la sociedad faraónica vivía y veía.

En este sentido, la victoria sobre el otro, lo diferente, el enemigo, está presente en la mentalidad egipcia con anterioridad incluso a la Paleta de Narmer. Al respecto son muy interesantes las reflexiones de Di Paolo (2016) sobre si en el arte mesopotámico los textos, incluidos los militares, servían para reforzar la memoria oral y todo aquello que era conocido, y esperado, por la población y sociedad, ¿pueden tener muchos textos y escenas faraónicas la misma función? Posiblemente fue así, pero dichos textos y escenas siempre se han interpretado como hechos históricos, se ha querido buscar una historia, cuando pueden ser un reflejo de lo que se esperaba y se debía transmitir para proteger y mantener la memoria cultural.

En relación con ello el planteamiento de Assmann recoge la idea de Hornung (1966) en el sentido de que los textos y las grandes inscripciones reales deben considerarse como un reflejo de lo que él llama el sentido de historia como festival que tenían los antiguos egipcios; lo que deseaban era transmitir un mensaje, no una historia, una interpretación que no es aceptada por Schneider (2014).

La conclusión que podría aducirse es que hay un pasado que esta inherente en todo lo que se efectúa, lo que puede cambiar es la forma de transmitir lo realizado, que se puede hacer con mayor o menor detalle, de una forma más visible o no, en una gran construcción o no, pero siempre se debe tener en cuenta el contexto histórico, la intencionalidad de lo que se transmite y a quién y para qué va dirigido el mensaje.

Siempre hay un elemento histórico que se vincula con la tradición y legitima, justifica el presente a través de la memoria cultural que se ha ido formando con el paso del tiempo y que, en el caso del antiguo Egipto, no solo responde a la intención de las élites gobernantes, de sus faraones, sino también a las realidades que se habían vivido desde tiempos predinásticos.

Es por ello que en ocasiones manifestaciones del mundo faraónico, en especial las concernientes a su imagen visual que es su memoria visual, suelen ser calificadas como arcaísmo, residiendo en ello igualmente la idea de Platón de que nada cambió o evolucionó en un mundo egipcio repetitivo, pero que hay que entender como manifestaciones de una memoria cultural que se va adaptando en todo momento a las circunstancias y necesidades con una base común (Wendrich, 2013).

Como breve reflexión final también habría que mencionar cómo esa memoria cultural que encontró en los templos, en las tumbas, en los textos e imágenes su medio de expresión perduró gracias a lo que el mundo grecorromano, y en cierta medida el relato bíblico, nos transmitió del mundo faraónico. Imágenes que se corresponden con la victoria, el colosalismo, un mundo próspero y exótico en sus costumbres y creencias que siguen constituyendo el retrato que de lo faraónico se tiene en la actualidad.

Es por ello por lo que cada vez resulta más necesario una visión antropológica del mundo faraónico. Este es el gran mérito del camino abierto por J. Assmann, parafraseando una de sus obras, (Assmann, 2005b) buscar el sentido de su historia.

\section{Reflexiones finales}

El concepto de eternidad siempre estuvo presente en el mundo faraónico pero el mismo tenía dos términos que representaban nociones diferentes. Por un lado, estaba djet, que refleja todo lo que 
existía desde la eternidad, lo que fue creado en los orígenes, por lo tanto, es el pasado que conduce al presente, mientras que neheh es la eternidad hacia el futuro. La primera era la que existía, era visible y, podría decirse que había ido formando la memoria cultural del mundo faraónico, pero la segunda se adentra en el futuro, en lo cíclico y fuera por lo tanto de lo lineal, en definitiva, es lo que se espera conseguir o alcanzar (Servajean 2007).

Una dualidad que estuvo presente en muchas de las manifestaciones del Egipto faraónico, que siempre buscó explicar y dotar de un sentido a su historia y cultura, a cómo vivían y por qué.

Como hemos esbozado en las páginas anteriores, la memoria cultural del antiguo Egipto arranca en tiempos predinásticos con todas las experiencias que vivieron y tuvieron que superar hasta llegar a poner las bases de un Estado territorial gobernado por un faraón.

Desde esos inicios reflejaron en sus templos, textos y manifestaciones visuales su memoria, lo que les permitía legitimar el presente. Unas realidades que rodeaban al mundo faraónico que el conjunto de la sociedad las conocía y sentía como propias, aunque los faraones pronto comenzaron a plasmar dicha memoria de una forma diferente, cada vez más colosal, en sus tumbas y en los templos.

Durante toda su historia la memoria cultural era percibida visualmente, sentida en los rituales y vivida anualmente con el ciclo de la crecida del Nilo.

Esa interiorización que tenían los antiguos egipcios de su pasado, de su memoria cultural, explica que los reyes ptolemaicos se vieran forzados a emprender una ambiciosa política constructora, en especial en el Alto Egipto, donde precisamente las tradiciones, la memoria cultural siempre estuvo más presente, también en el Bajo Egipto, pero allí las relaciones con un mundo mediterráneo dieron lugar a expresiones diferentes.

Es por ello por lo que Assmann piensa que son los templos de época baja los principales exponentes de la memoria cultural faraónica, aunque la misma existiera desde los orígenes y es lo que también ayuda a entender cómo lo que llamamos cultura faraónica pervivió más de tres milenios y, con posterioridad, traspasó los límites de Kemet para extenderse y llegar a nuestros días con unas imágenes e ideas que debemos entender en su contexto, no en el nuestro.

\section{Bibliografía}

Assmann, J. (1977). Die Verborgenheit des Mythos im Alten Ägypten. Göttinger Miszellen, 25, 7-43. Assmann, J. (1991). Stein und Zeit. Mensh und Gesselbchaft im Alten Ägypten. München: Wilheim Fink.

Assmann, J. (1999). Cultural and literary texts. En Moers G. (ed.), Egyptian literature, Lingua Aegyptia, Studia Monographica 2 (pp. 1-15). Hamburg: Verlag Widmaier.

Assmann, J. (2005a). Das kulturelle Gedächtnis. München: Beck.

Assmann, J. (2005b). Egipto. Historia de un sentido. Madrid: Abada.

Assmann, J. (2006). La distinción mosaica o el precio del monoteísmo. Madrid: Akal.

Assmann, J. (2008). Communicative and Cultural Memory. En Cultural Memory Studies. An International and Interdisciplinary Handbook (pp. 109-118). Berlín: Walter de Gruyter.

Assmann, J. (2011). Historia y Mito en el Mundo Antiguo. Los orígenes de la cultura en Egipto, Israel y Grecia. Madrid: Gredos.

Assmann, J. (2017). Religio duplex. Misterios egipcios e llustración europea. Madrid: Akal.

Baines, J. (1989). Ancient Egyptian concepts and uses of the past: third to second millennium evidence. En R. Layton (ed.), Who Needs the past? Indigenous values and archaeology (pp. 131-149). London: Routledge.

Baines, J. (1997). Temples as symbols, guarantors and participants in Egyptian civilization. En S. Quirke (ed.), The Temple in Ancient Egypt (pp. 216-241). London: British Museum.

Baines, J. (2003). Research on Egyptian literature: background. Definitions, prospects. En Z. Hawass y L. Pinch (eds.), Egyptology at the dawn of the twenty-first Century (pp. 1-47). El Cairo: American University in Cairo. 
Baines, J. (2007a). Visual and Written Culture in Ancient Egypt. Oxford: Oxford University Press.

Baines, J. (2007b). "Orality and literacy". Visual and Written Culture in Ancient Egypt (pp. 146-178). Oxford: Oxford University Press.

Baines, J. (2008). On the evolution, purpose and forms of Egyptian Annals. Zeichen aus dem Sand. Streiflichter aus Ägyptens Geschichte zu Ehren von Günter Dreyer (pp. 19-40). Wiesbaden: Harrassowitz.

Baines, J. y Eyre, C. (1983). Four notes on literacy". Göttinger Miszellen, 61, 65-96.

Bietak, M. (2018). Introduction to palaces in Egypt: what they tell us about the Ruler, administration and Culture. En M. Bietak y S. Preel (eds.), Palaces in Ancient Egypt and the Ancient Near East, vol. 1 (pp. 23-38). Vienna: Verlag der Österreichischen Akademie der Wissenschaften.

Bussmann, R. (2016). Great and Little traditions in Egyptology. En Königtum, Staadt und Gesellschaft Früher Hochkulturen (pp. 37-48). Wiesbaden: Harrassowitz.

Butler, S. \& Bradley, M. (2019). The Senses in Antiquity. London: Routledge.

Buxton, R. (1994). Imaginary Greece. The contexts of Mythology. Cambridge: Cambridge University Press.

Cavillier, G. (2013). Ramesses III's wars and triumphs at Medinet Habu. Between narration, history and identity. En A. Spalinger y J. Armstrong (eds.), Rituals of Triumph in the Mediterranean World (pp. 23-36). Leiden: Brill.

Chaniotis, A. (2006). Rituals between Norms and Emotions. Rituals as shared Experience and Memory. Kernos suppl. 16, 211-38.

Di Paolo, S. (2016). War remembrance narrative. Negotiation of memory and oblivion Mesopotamian art. En D. Nadali (ed.), Envisioning the Past through Memories. How Memory Shaped Ancient Near Eastern societies (pp. 146-162). London: Bloomsbury.

El-Daly, O. (2005). Egyptology. The missing millennium, ancient Egypt in medieval Arabic writings. London: University College of London.

Erll, A. (2011). Memory in Culture. New York: Palgrave Macmillan.

Frangipane, M. (2018). Different trajectories in State formation in Greater Mesopotamia: A view from Arslantepe (Turkey). Journal of Archaeological Research, 26(1), 3-63.

Frankfurter, D. (1998). Religion in Roman Egypt. Assimilation and Resistance. Princeton: Princeton University Press.

Friedman, R. (2009). Hierakonpolis locality HK29A. The predynastic ceremonial center revisited. Journal American Research Center in Egypt, 45, 79-103.

Goebs, K. (2002). A functional approach to Egyptian myth and mythemes, Journal of Ancient Near Eastern Religions, 2, 27-59.

Griffiths, J. (1970). Plutarch's De Iside et Osiride. Cardiff: University of Wales.

Harrington, N. (2012). Living with the Dead. Ancestor Worship and Mortuary Ritual in Ancient Egypt. Oxford: Oxbow.

Harth, D. (2008). The Invention of Cultural Memory. Cultural Memory Studies. An international and Interdisciplinary Handbook (pp. 85-96). Berlin: de Gruyter.

Hartung, U. (2018). Cemetery U at Umm el-Qaab and the funeral Landscape of the Abydos Region in the $4^{\text {th }}$ Millennium BC. Desert and the Nile. Prehistory of the Nile Basin and the Sahara. Papers in honour of Fred Wendorf (pp. 313-335). Cracovia: Studies in African Archaeology.

Hays, H. (2009). Between Identity and agency in ancient Egyptian ritual. En R. Nyord y A. Kjolby (eds.), Being in Ancient Egypt. Thoughts on Agency, Materiality and Cognition (pp. 14-30). Oxford: BAR International Series.

Heagy, T. (2014). Who was Menes?. Archéo-Nil, 24, 59-92.

Heinz, M. y Feldman, M. (Eds.) (2007). Representations of Political Power. Case studies from Times of Change and Dissolving Order in the Ancient Near East. Pennsylvania: Eisenbrauns.

Hornung, E. (1966). Geschichte als Fest. Zwei Vorträge zum Geschichtsbild der frühen Menscheit. Darmstadt: Wissenschaftliche Buchgesellschaft.

Kahl, J. (2010). Archaism. En W. Willeke (ed.), UCLA Encyclopedia of Egyptology. Los Angeles, CA: 
University of California. Recuperado de http://digital2.library.ucla.edu/viewltem.do?ark=21198/ zz0025qh2v

Liverani, M. (1990). Prestige and Interest. International relations in the Near East ca. 1600-1100 BC. Padova: Sargon.

Loprieno, A. (Ed.) (1996). Ancient Egyptian Literature. History and Forms. Leiden: Brill.

Mathieu, B. (2011). Seth polymorphe: le rival, le vaincu, l'auxiliaire. ENIM, Égypte Nilotique et Méditerranéene , 4, 137-158.

Malek, J. (1992). A meeting of the Old and New: Saqqara during the New Kingdom. En A. Lloyd (ed.), Studies in Pharaonic Religion and Society in Honour of J. Gwyn Griffiths (pp. 61-66). London: Egypt Exploration Society.

Manning, J. (2017). Cross-cultural Communication in Egypt. En R. Talbert y F. Naiden (eds.), Mercury's Wings. Exploring modes of Communication in the Ancient World (pp. 271-288). Oxford: Oxford Scholarschip Online.

Morris, E. (2013). Propaganda and Perfomance at the Dawn of the State. Power, generating authority, cosmos, politics and the ideology of Kingship in Ancient Egypt and Mesopotamia (pp. 33-64). Pennsylvania: University Pennsylvania Press.

O’Connor, D. y Silverman, D. P. (eds.) (1995). Ancient Egyptian Kingship. Leiden: Brill.

Parkinson, R. (2002). Poetry and Culture in Middle Kingdom Egypt. A Dark side to Perfection. London: Equinox.

Peden, A. (2001). The Graffiti of Pharaonic Egypt. Scope and Roles of informal writings (c. 3100332BC). Leiden: Brill.

Piquette, K. (2018). An Archaeology of Art and Writing. Early Egyptian Labels in Context. Cologne: Modern Academic Publishing. DOI: https://doi.org/10.16994/bak

Pongratz-Leisten, B. (2019). Ideology. En A. Gunter (ed.), A Companion to Ancient Near Eastern Art (pp. 283-308). Oxford: Wiley Blackwell.

Quirke, S. (2105). Exploring Religion in Ancient Egypt. Oxford: Wiley Blackwell.

Ristvet, L. (2015), Ritual, Performance, and Politics in the Ancient Near East. Cambridge: Cambridge University Press.

Robins, G. (1993). Women in Ancient Egypt. Harvard, MA: Harvard University Press.

Servajean, F. (2007). Djet et Neheh: Une histoire du temps égyptien. Orientalia Monspeliensia (vol. 18). Montpellier: University Paul-Valérey.

Shafer, B. (ed.) (2005). Temples of Ancient Egypt. London: I. B. Tauris.

Schneider, T. (2014). History as Festival? A Reassessment of the use of the past and the place of Historiography in Ancient Egyptian Thought. En J. Raaflaub (ed.), Ancient World. Comparative Studies. Thinking, recording and writing history in the Ancient World (pp. 117-143). Oxford: Wiley Blackwell.

Spencer, N. (2010). Priests and Temples. Pharaonic. En A. Lloyd (ed.), A Companion to Ancient Egypt (pp. 255-273). Oxford: Wiley Blackwell.

Stadler, M. (2008). Procession. En J. Dieleman y W. Wendrich (eds.), UCLA Encyclopedia of Egyptology. Los Angeles, CA: University of California. Recuperado de http://repositories.cdlib. org/nelc/uee/1014

Stephan, T. (2017). Writing the past. Ancient Egypt through the lens of Medieval Islamic thought. En J. Lowry y S. Toorawa (eds.), Arabic Humanities, Islamic thought, Essays in Honor of Everett K. Rowson (pp. 256-270). Leiden: Brill.

Stevens, A. (2015). Visibility, private religion and the urban landscape of Amarna. Seen \& unseen spaces, Archaeological Review from Cambridge, 30(1), 77-84.

Stern, S. (2012). Calendars in Antiquity. Empires, States and Societies. Oxford: Oxford University Press.

Teeter, E. (2011). Religion and Ritual in Ancient Egypt. Cambridge: Cambridge University Press.

Van de Mieroop, M. (2012). The Mesopotamian and their past. En J. Wiesehöfer y T. Krüger (eds.), Periodisierung und Epochen-bewusstsein im Alten Testament und in seinem Umfold (pp. 37- 
56). Zurich: Franz Steiner Verlag.

Waerzeggers, C. (2011). The Pious king. Royal Patronage of Temples. Oxford Handbook of Cuneiform Culture (725-751). Oxford: Wiley Blackwell.

Wagoner, B. (2017). Handbook of Culture and Memory. Oxford: Oxford University Press.

Wendrich, W. (2013). Antiquarianism in Egypt. The importance of re. En A. Schnapp (ed.), World Antiquarianism. Comparative perspectives (pp. 140-158). Los Angeles, CA: Getty Research Institute.

Wilkinson, T. (2016). Power and authority in Early Dynastic Egypt. En J. van Dijk (ed.), Another Mouthful of Dust. Egyptological Studies in Honour of G.T. Martin (pp. 543-557). Orientalia Lovaniensia Analecta 246. Leiden: Brill.

Williams, B. y Logan, T. (1987). The Metropolitan museum knife handle and aspects of Pharaonic imagery before Narmer. Journal of Near Eastern Studies, 46(4), 245-85.

Yoffee, N. (2005). Myths of the archaic state. Evolution of the Earliest Cities, States and Civilizations. Cambridge: Cambridge University Press.

Yoffee, N. (ed.) (2015). Early Cities in Comparative Perspective: 4000 BCE-1200 CE. Cambridge: Cambridge University Press. 



\section{Panta Rei}

PANTA REI es una revista digital de investigación orientada a la Historia y otras ciencias afines. Su principal objetivo es la transmisión del conocimiento científico, dando una oportunidad también a los jóvenes investigadores que quieren abrirse camino en el estudio de las ciencias humanas y sociales. Se compone de estudios originales relacionados con la disciplina histórica así como su didáctica y difusión. Las diferentes secciones que componen la revista son: artículos de investigación, entrevistas a profesionales, recensiones de monografías de actualidad y crónicas de congresos o eventos científicos relevantes.

Todos los artículos publicados son objeto de un proceso de revisión a cargo de un mínimo de dos evaluadores, que se consideran expertos en el ámbito temático del artículo propuesto. Nuestro deseo es poder ofrecer unos contenidos rigurosos, de calidad y de interés.

EI CEPOAT (Centro de Estudios del Próximo Oriente y la Antigüedad Tardía de la Universidad de Murcia) es la institución encargada de la coordinación y gestión de la revista, desde donde anualmente se lanzará la convocatoria para aquellos que estén interesados en publicar sus trabajos, siempre relacionados con la Historia, Arqueología, Historia del Arte, Didáctica de la Historia, etc.

PANTA REI is a digital journal focused on History and other sciences related to it. Its main objective is the transmission of scientific knowledge by giving also an opportunity to young researchers who want to make their way in the study of human and social sciences. It is composed by original studies related to History, as well as its didactics and promotion. The different sections of this journal are: research articles, interviews to professionals, recensions on monographs about current issues and reports about congresses or relevant scientific events.

All the articles published are subject to a revision process carried out by a minimum of two reviewers who are considered to be experts in the field of the article proposed. Our wish is to offer rigorous contents with quality and being of interest to the reader.

CEPOAT (Centre of Studies of the Middle East and Late Antiquity of the University of Murcia) is the institution in charge of the coordination and management of this journal. This is the centre from where the call for papers will be launched for all the people interested in publishing their papers, always related to History, Archeology, Art History, Teaching History, etc. 


\section{Normas de Publicación}

El autor se compromete a enviar trabajos originales, que no se encuentren publicados en otras revistas ni en otros idiomas. Así mismo, el mismo artículo no podrá ser presentado en otras revistas mientras dure el proceso de evaluación.

\section{Envío y presentación de originales}

Los artículos se enviarán exclusivamente a través del correo electrónico a la dirección pantarei@um.es. Los textos serán enviados en formato DOC y las imágenes en formato JPEG o TIFF, y con un tamaño mínimo de 2000 px. Éstas no aparecerán incorporadas en el texto, sino enviadas en archivo aparte y correctamente numeradas según su posición en el texto. Junto al trabajo, se rellenará y enviará un documento aparte en el que se especifiquen los datos del autor siguiendo el modelo disponible en la página Web de la revista.

Para la redacción de los trabajos se tendrá en cuenta el Manual de la American Psychological Association, en su sexta edición. La extensión máxima de los trabajos será de 30 páginas. La tipografía será Arial 11, con interlineado sencillo y sin espacio alguno entre párrafos. El texto deberá ir justificado a ambos márgenes y sin sangría en los primeros párrafos. Los márgenes serán de $2,50 \mathrm{~cm}$. En los casos en los que fuera necesario incorporar notas, éstas irán a pie de página, enumeradas consecutivamente, con tipografía Arial 10, interlineado sencillo y justificadas a ambos márgenes.

Una información más detallada se encuentra disponible en la página http://www.um.es/cepoat/ pantarei.

\section{Proceso de valoración y evaluación}

Una vez recibidos los trabajos, la Revista realizará una primera valoración. Si el trabajo enviado se ajusta a las normas de presentación propuestas, la temática es coincidente con la línea editorial de la revista y posee la calidad científica necesaria, será remitido al consejo asesor para una primera evaluación. Si no es así en este primer paso se puede rechazar directamente los documentos que incumplan claramente la línea editorial.

Será el Consejo Asesor quien indique a la revista la originalidad, relevancia, estructura, redacción, aparato bibliográfico, etc. del trabajo enviado y, para ello, se designará a dos revisores expertos externos que evaluarán cada uno de los trabajos, que pueden formar parte (o no) de este Consejo Asesor. La selección de los revisores se ajustará a la temática y características metodológicas del trabajo. El nombre y filiación de los autores serán eliminados del trabajo para su revisión, así como los revisores actuarán de manera anónima y confidencial.

Los revisores deberán rellenar un informe de evaluación que centrará su atención en aspectos tales como características formales, originalidad y novedad de los trabajos, relevancia de las propuestas y los resultados, calidad metodológica y validez científica.

Una vez terminado el proceso se decidirá la aceptación o no de los mismos y su publicación en el número que sea pertinente, así como las modificaciones susceptibles de ser realizadas para su final publicación. Dicha notificación se enviará únicamente por correo electrónico, en un plazo máximo de seis meses. 


\section{Publishing rules}

The author is committed to submit original papers not having been published in other reviews or in other languages. In this way, it is not allowed for the same paper to be presented in other reviews during the evaluation process.

\section{Submission and presentation of originals}

The articles will be exclusively submitted by email to pantarei@um.es. The texts will be submitted in DOC format and the images in JPEG or TIFF format, and with a minimum size of 2000 px. Images will not be integrated in the text but sent in another file and properly numbered according to their position in the text. Attached to the paper, a document will be filled out and sent where the author's data will be specified following the model available on the website.

The sixth edition of the Manual of the American Psychological Association will be taken into account for the writing of the papers. The length of the papers must not exceed 30 pages. Typography will be Arial 11 , with simple line spacing and no space between paragraphs. The text must be justified on both margins without indentation in the first paragraphs. Margins size will be $2.50 \mathrm{~cm}$. Where it could be necessary the incorporation of notes, they will be at the bottom of the page, consecutively numbered with typography Arial 10, simple line spacing and justified on both margins.

More detailed information is available on the website: http://www.um.es/cepoat/pantarei.

\section{Examination and assessment process}

The Journal will submit the papers to a first examination once received. If the paper follows the presentation guidelines, the subject agrees with the editorial line of this journal, and possess the scientific quality required, it will be sent to the advisory council for a first assessment. If not, the documents which clearly fail to complete the editorial line may be rejected straightaway in this first step.

The Advisory Council will indicate the originality, relevance, structure, writing, bibliography, etc. of the text to the journal; for this purpose, two outside experts will be designated to review the papers; these experts can be (or not) part of this Advisory Council. The selection of the experts will adjust to the subject and methodological characteristics of the paper. Name and affiliation of the author will be eliminated from the text for its review, in this way experts will act anonymously and confidentially.

The experts will fill out an assessment report which will focus on aspects such as formal characteristics, originality and novelty of the papers, relevance and results of the proposal, methodological quality and scientific validity.

Once the process is finished, the acceptance or not of the papers and its publication in the corresponding edition will be decided, as well as the modifications that may be done for its final publication. This notification will be sent by email within 6 months maximum. 


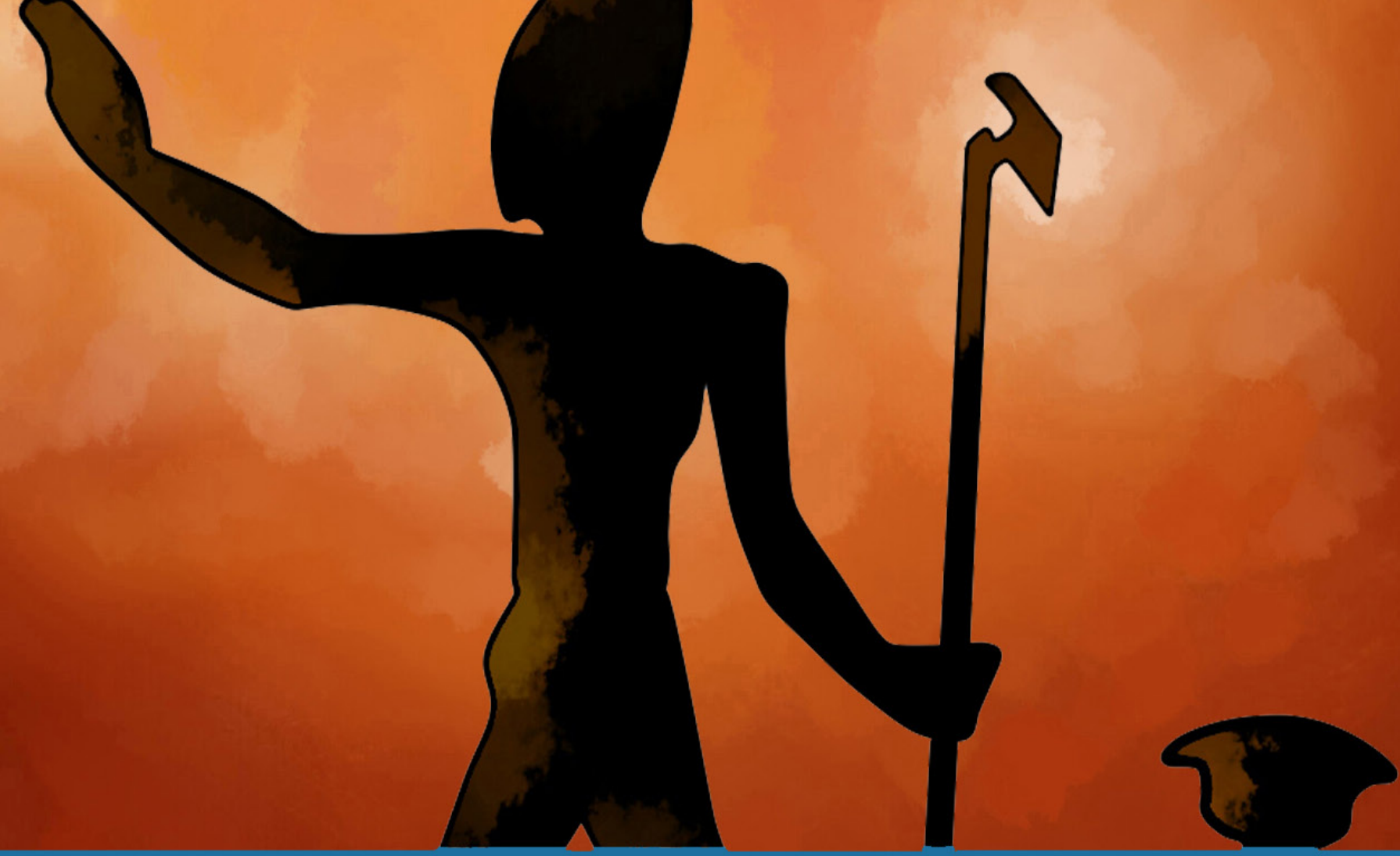

GepOA

centro de estudios de

próximo oriente y la

antigüedad tardía 